\title{
Tackling Uterine Inversion, a Rare Obstetric Tragedy- A Case Series
}

\author{
Naima Afreen ${ }^{1 *}$, Mayuri Ahuja ${ }^{2}$, Pramila Yadav ${ }^{3}$, Shehla Jamal ${ }^{4}$, Samta Gupta ${ }^{5}$, Nimmi Chutani ${ }^{6}$ \\ ${ }^{1,2,4}$ Assistant Professor, Department of Obstetrics and Gynecology, School of Medical Sciences and Research, Sharda University. Greater Noida, India \\ Assistant Professor, Department of Obstetrics and Gynecology, School of Medical Sciences and Research, Sharda University, Greater Noida, India \\ ${ }^{3}$ Consultant, Metro Hospital, Obstetrics and Gynecology, Gorakhpur, India \\ ${ }^{5,6}$ Professor, Department of Obstetrics and Gynecology, School of Medical Sciences and Research, Sharda University, Greater Noida, India
}

DOI: $10.36348 /$ SIJOG.2019.v02i09.001

| Received: 03.09.2019 | Accepted: 18.09.2019| Published: 28.09.2019

*Corresponding author: Dr. Naima Afreen

\section{Abstract}

Acute uterine inversion is a rare and life-threatening entity. Incidence varies widely from 1:2,000 to 1:23,000 deliveries. It is folding of the fundus into the uterine cavity so that the uterus is turned inside out. Most cases of uterine inversion occur due to mismanagement of third stage of labor. Classical presentation is postpartum hemorrhage and associated profound shock. Correct and early diagnosis coupled with employment of early resuscitation measures together with attempt to replace the uterus either manually or by hydrostatic method is the key to success to their management. We share our experience of such series of cases who presented at our tertiary care center between August 2013 to October 2018.

Keywords: Acute inversion, active management of third stage, obstetric emergency.

Copyright @ 2019: This is an open-access article distributed under the terms of the Creative Commons Attribution license which permits unrestricted use, distribution, and reproduction in any medium for non-commercial use (NonCommercial, or CC-BY-NC) provided the original author and source are credited.

\section{INTRODUCTION}

Uterine inversion is an introflexion of parietes uteri occurring mainly during third or fourth stage of labor [1]. Incidence varying between $1: 2,000$ to 1 : 23,000 deliveries and is associated with a high risk of mortality due to hemorrhage and shock [2, 3]. The incidence at our center is about 1: 1000 with mortality rate round about $33 \%$. There are four degrees of inversion.

First degree/Incomplete inversion: Fundus inverts but does not herniate through the level of the internal os.

Second degree/Complete inversion: The inverted fundus crosses through the cervical os.

Third degree/Prolapsed inversion: Entire uterus prolapsing through the cervix with the fundus passing out of the introitus.

Fourth degree/Total inversion: Inversion of the uterus and vaginal wall as well. Depending upon the time of presentation they can be classified as [4].
Acute: Twenty-four hours or less after delivery

Subacute Longer than 24 hours postpartum

Chronic: Longer than 1 month postpartum.

Mostly the presentation is with either hypovolemic or neurogenic shock post-delivery. Strong fundal pressure, strong traction exerted on the umbilical cord in adherent placenta, fundal implantation of the placenta and fundal fibroid are thought to be contributory factors. Other risk factors are short cord, precipitate labor and prolonged labor. Delay in referral, poor resources, poor transport facilities, non-availability of resuscitative measures at primary center are the major challenges. Proposed line of management are resuscitative measures along with replacement/ repositioning of uterus by either manual or hydrostatic method. Surgical method is employeed if above measures fail. The abdominal methods areHuntington's procedure and Haultin's procedure and vaginal methods are - Spinelli's method and Kustner method. Laparoscopic man agent of puerperal uterine inversion has also been documented [5]. 


\section{CASE SERIES}

\section{CASE 1}

26 years P1L1 presented with complaints of heavy menstrual bleeding and discharge per vaginum for $3 y$ rs. She gave the history of home vaginal delivery in 2013 which was followed by uterine inversion that was repo sited manually at a government. On examination $5 \times 5 \mathrm{~cm}$ mass was present in the vagina with bleeding points on surface. Uterus was not felt on vaginal examination and fingers can't be insinuated between cervical lip \& the mass. Chronic Inversion was diagnosed. She was managed successfully with Haultain's operation.

\section{CASE 2}

20 years P2L2 presented $5 \mathrm{hr}$ after vaginal delivery at private hospital with massive PPH in shock at $8: 15 \mathrm{pm}$ on $11 / 8 / 13$. Examination showed complete uterine inversion. Resuscitation followed by uterine repositioning was done manually as well as by hydrostatic method. Sub Total Hysterectomy was performed due to massive atonic PPH. Patient succumbed to cardiopulmonary arrest at $4: 30 \mathrm{am}$ on $12 / 8 / 13$.

\section{CASE 3}

30 years P2L2 presented 4 hours after home delivery with massive PPH and shock at 2am on 22/12/15. Examination showed complete uterine inversion. Along with resuscitation manual reposition \& Sullivan hydrostatic method was performed but was unsuccessful. Uterine repositioning was done by Huntington's method. Patient had good post-operative recovery.

\section{CASE 4}

30 years P4L4 presented $4 \mathrm{hrs}$ after home delivery in profound shock with massive PPH at 2:30 am on $8 / 5 / 15$. Examination revealed complete uterine inversion. She had cardiac arrest within $7 \mathrm{~min}$ of admission and could not be revived.

\section{CASE 5}

23 years G4P3L3 with 39wks pregnancy presented in 2nd stage of labor on 12/7/16 at 7:25 am and delivered a good size baby. With delivery of placenta uterine inversion occurred and the cord was found short. Uterus was immediately reposted back manually and uterotonics were given. The management was successful and patient revived.

\section{CASE 6}

22 years $\mathrm{P} 1 \mathrm{~L} 1$ presented $4-5$ hours after home delivery with PPH and shock on 6/8/16 at 3:30pm. On examination fleshy mass was seen in vagina and traumatic PPH was present

Manual reposition of uterus \& O'sullivan tried but failed. Laparotomy performed; inversion was corrected by Huntington's method. Hayman's compression sutures applied for atonic PPH. Vaginal tear repaired. She survived and had good post op recovery.

\section{CASE 7}

25 years P3L3 presented 4hrs after delivery at a nursing home with profound shock and massive PPH at $1: 45 \mathrm{am}$ on $12 / 10 / 16$. On examination a fleshy mass of $8 X 8 \mathrm{~cm}$ seen in the vagina. Diagnosis of Acute uterine inversion was made. Resuscitation along with manual reposition and O' Sullivan's attempted but was not successful. Inversion was corrected by Huntington's method but due to atonic PPH, hysterectomy was performed. Despite these measures' patient succumbed to cardiac arrest.

\section{CASE 8}

21years P2L2 presented 5hrs after vaginal delivery at a private hospital in shock with severe PPH \& severe anemia on $11 / 9 / 18$ at $3 \mathrm{am}$. Examination revealed acute uterine inversion. Resuscitation along with manual reposition \& O' Sullivan tried was performed but was not successful. Uterus was reposited by Huntington's method. Modified B'Lynch sutures and intrauterine Foley's tamponade was done for correction of atonic PPH. Pt survived and made a very good post op recovery.

\section{CASE 9}

23 years P2L2 presented 3.5hrs after vaginal delivery at Govt. hospital in shock with severe PPH with a referral note of acute uterine inversion with failure of manual reposition on 24/9/18. Resuscitation along with manual reposition \& O'sullivan tried but uterus was reposited by Huntington's method. Patient had a good post-operative recovery.

Table-1: Demographic characterisctics, presentation and management of the series of cases

\begin{tabular}{|c|c|c|c|c|c|c|c|c|c|}
\hline Factors & CASE1 & CASE2 & CASE3 & CASE4 & CASE5 & CASE6 & CASE7 & CASE8 & CASE9 \\
\hline Age(Years) & 20 & 30 & 30 & 30 & 23 & 22 & 25 & 21 & 23 \\
\hline Parity & 1 & 2 & 2 & 4 & 4 & 1 & 3 & 2 & 2 \\
\hline $\begin{array}{l}\text { Time lag (Hours) after } \\
\text { delivery }\end{array}$ & - & 5 & 4 & 4 & Immediate & 4.5 & 4 & 5 & 3.5 \\
\hline Manual Reduction & - & failed & failed & - & achieved & failed & failed & failed & failed \\
\hline Hydrostatic method & & failed & failed & _ & & failed & failed & failed & failed \\
\hline Surgical Management & Haultain's & $\checkmark$ & $\checkmark$ & - & $\mathrm{X}$ & $\checkmark$ & $\boldsymbol{V}$ & $\checkmark$ & $\checkmark$ \\
\hline Survived & $\checkmark$ & $\mathrm{X}$ & $\checkmark$ & $\mathrm{X}$ & $\checkmark$ & $\checkmark$ & $\mathrm{X}$ & $\checkmark$ & $\checkmark$ \\
\hline
\end{tabular}




\section{DISCUSSION}

Uterine inversion is an extremely rare, serious and critical condition which is life threatening. It leads to maternal mortality if immediate appropriate treatment is not started. The prevalence of Acute, Sub acute and chronic uterine inversion is $83.4 \%, 2.62 \%$ and $13.9 \%$ respectively [6]. The incidence at our center is 1.8: 1000. Despite encouraging institutional deliveries by trained birth attendants there is a high incidence of unsupervised home deliveries in India especially in remote and underprivileged areas of the country. Poor referral and transport facilities further remain a challenge in rural India. Most cases of acute uterine inversion results from mismanagement of third stage of labor in women who are already at risk. Uterine inversion is rarely seen in non-pregnant uterus is relation to the expulsion of fibroid polyp. Exact cause of uterine inversion is not known but the principle behind its occurrence is that cervix is dilated and uterine fundus is relaxed. In Complete inversion cervix functions as a constricting band and edema rapidly forms. The prolapsed mass then progressively enlarges $\&$ obstructs venous \& finally arterial flow, contributing to the edema which makes manual reduction difficult. The earlier the patient presents the easier is the reduction manually or by hydrostatic method. Diagnosis is mainly clinical based on the signs and symptoms but one has to have a keen eye to diagnose this entity when a patient is brought post-delivery with PPH and shock. Acute uterine inversion requires prompt management. Correction of shock along with a trial of manual reduction is the key to success [7]. HJ Philipe et al. recommended usage of neuromuscular relaxant substance as magnesium sulphate to facilitate manual reduction. Presently, nitrate-based products are mostly used through intravenous route as they allow a rapid relaxation of the cervix [8]. General anesthesia is indicated when muscular relaxant drugs fail. In all the cases at our institution no relaxant was given. If manual reduction fails, O' Sullivan Hydrostatic method is attempted. In Ogueh and Ayida technique IV tubing is attached to silicone cup used in vacuum extraction. By placing the cup in the vagina, an excellent seal is created. Only one case responded by manual reduction and the hydrostatic pressure did not bear fruitful results in our cases. Failure of the above procedure makes the surgical approach imperative. In our cases of acute inversion, we used the Huntington technique in which stepwise traction on the funnel of the inverted uterus or the round ligament is given with Allis. The Haultain technique is indicated in case of failure of the above. It consists of an incision made posteriorly through the cervix, relieving cervical constriction to increase the size of the ring allowing traction on the round ligament for the replacement of uterus with subsequent repair of incision from inside the abdomen. The Spinelli method consisting of anterior median colpohysterotomy through the vaginal access allows removal of the cervical restriction. Hysterectomy is indicated as a life-saving procedure for non-responding atonic $\mathrm{PPH}$ or for a gangrenous uterus and should be the last resortment [8, 9]. Scanty data is available in literature about uterine inversion hence awareness about this condition and reporting of such cases should be encouraged so as to prevent and once diagnosed prompt management of this obstetric tragedy should be done.

\section{CONCLUSION}

Education and training of traditional birth attendants and medical personnel regarding active management of third stage of labor should be propagated. There is need for incorporation of management of uterine inversion into skills and drills training for young obstetricians as it are one of the preventable obstetric emergencies.

\section{ACKNOWLEDGEMENT}

I am thankful to my seniors and colleagues of this institution for encouraging me to write this case series.

\section{REFERENCES}

1. Studziński, Z., \& Branicka, D. (2001). Acute complete uterine inversion--care report. Ginekologia polska, 72(11), 881-884.

2. Thakur, M., \& Thakur, A. (2019). Uterine Inversion. In StatPearls [Internet]. StatPearls Publishing.

3. Wendel, M. P., Shnaekel, K. L., \& Magann, E. F. (2018). Uterine Inversion: A Review of a LifeThreatening Obstetrical Emergency. Obstetrical \& gynecological survey, 73(7), 411-417.

4. Eddaoudi, C., Grohs, M. A., \& Filali, A. (2018). Uterine inversion: about a case. The Pan African medical journal, 29, 99-99.

5. GAO, J. L., Lortie, K., \& Singh, S. S. (2010). Laparoscopic internal iliac artery ligation for postpartum spontaneous hemoperitoneum. Journal of Obstetrics and Gynaecology Canada, 32(12), 1172-1175.

6. Dali, S. M., Rajbhandari, S., \& Shrestha, S. (1997). Puerperal inversion of the uterus in Nepal: case reports and review of literature. Journal of Obstetrics and Gynaecology Research, 23(3), 319325.

7. Wendel, P. J., \& Cox, S. M. (1995). Emergent obstetric management of uterine inversion. Obstetrics and gynecology clinics of North America, 22(2), 261-274.

8. Philipe, H. J., Goffinet, F., Jacquemart, F., Morel, B., Grall, J. Y., \& Lewin, D. (1991). Les traitements des inversions utérines obstétricales à propos de trio's observations. J Gynecol Obstet Biol Reprod, 20, 843-849.

9. Thoulon, J.M., Heritier, Ph, Muguet, D., Spiers, C., Lebrat, J., Dumont, M. (1980). L'inversion uterine. Rev Fr Gynecol Obstet, 75:321-6. 